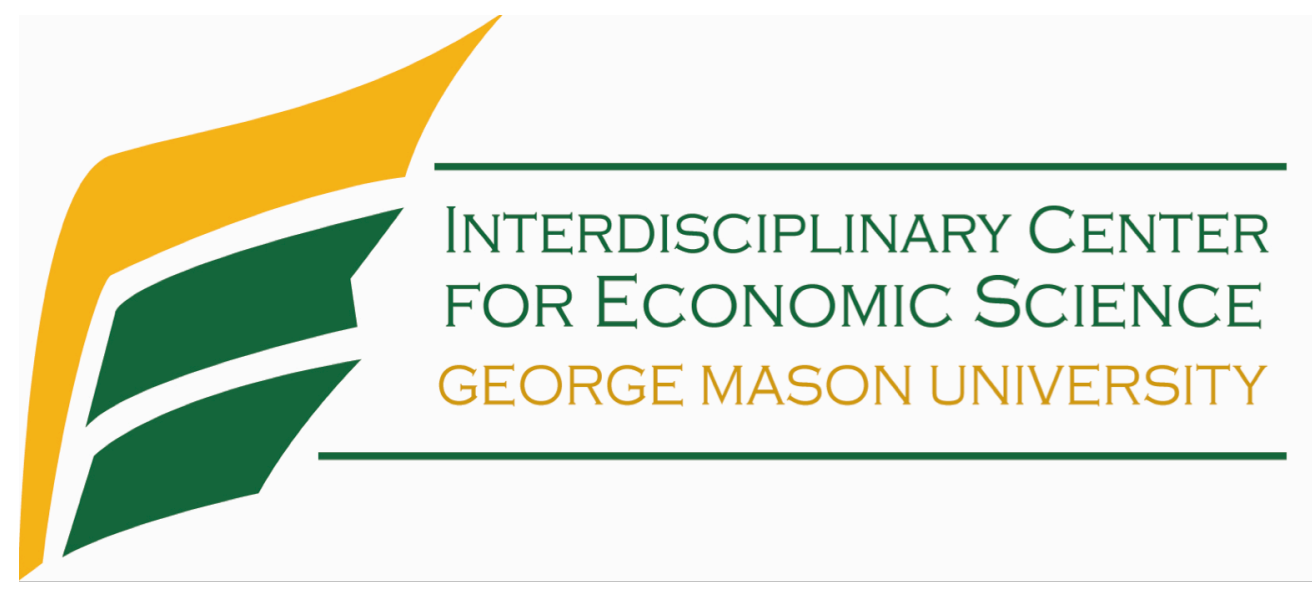

\title{
Revisiting Gender Differences in Ultimatum Bargaining: Experimental Evidence from the US and China
}

Shuwen Li, Xiandong Qin, and Daniel Houser

October 2017

Discussion Paper

Interdisciplinary Center for Economic Science

4400 University Drive, MSN 1B2, Fairfax, VA 22030

Tel: +1-703-993-4719 Fax: +1-703-993-4851

ICES Website: http://ices.gmu.edu

ICES RePEc Archive Online at: http://edirc.repec.org/data/icgmuus.html 


\title{
Revisiting gender differences in ultimatum bargaining: Experimental evidence from the US and China
}

\author{
Shuwen $\mathrm{Li}^{*}$ \\ Department of Economics and the Interdisciplinary Center for Economic Science, George Mason \\ University, Fairfax, VA, United States \\ Xiangdong Qin \\ Department of Applied Economics, Antai College of Economics and Management, Shanghai Jiao Tong \\ University, Shanghai, China \\ Daniel Houser \\ Department of Economics and the Interdisciplinary Center for Economic Science, George Mason \\ University, Fairfax, VA, United States
}

August, 2017

\begin{abstract}
We report results from a replication of Solnick (2001), which finds using an ultimatum game that, in relation to males, more is demanded from female proposers and less is offered to female responders. We conduct Solnick's (2001) game using participants from a large US university and a large Chinese university. We find little evidence of gender differences across proposer and responder decisions in both locations. We do however find that, in comparison to Chinese participants, US proposers are more generous, while US responders are more demanding.
\end{abstract}

Keywords: Gender differences, Cultural differences, Laboratory experiment, Ultimatum game, Bargaining

JEL Classification: C78, C92, J16, Z10

\footnotetext{
*Corresponding author. Email address: sli13@masonlive.gmu.edu.
} 


\section{Introduction}

Gender differences in bargaining are one source of persistent wage gaps in labor markets (Babcock and Laschever, 2003; Blau and Kahn, 2016). Early lab evidence of differences in bargaining between genders provided by Solnick (2001) may help to explain this. Using the ultimatum game with strategy method, she finds that female responders receive lower offers than male responders, and female proposers face higher minimum acceptable offers than male proposers. These patterns leave males earning significantly more than females.

Despite these intriguing early findings, experimental evidence on gender differences in bargaining is inconclusive (Croson and Gneezy, 2009; Güth and Kocher, 2014). Other studies conducted around the same time using different variants of the ultimatum game find different results. For example, Eckel and Grossman (2001) find the same pattern as Solnick (2001) in proposers' behavior, but both male and female responders are more likely to accept offers from female proposers. Also, Saad and Gill (2001) report that male proposers make more generous offers to female than male responders, while female proposers make equal offers independent of the gender of the recipient. Various other studies in the lab and field suggest, generally, that females obtain worse bargaining outcomes than males in a variety of contexts (see, e.g., Sutter et al, 2009; Dittrich et al., 2014; Ayres and Siegelman, 1995). An exception is Castillo et al. (2013), who find males receive higher prices from taxicab drivers than females in Lima.

This paper contributes to the literature on gender differences in bargaining by reporting a replication study of Solnick (2001) using student subjects from both the United States and China. Subjects play a two-person ultimatum game using a strategy method in which the proposer and the responder in a pair specify the offer and the minimum acceptable offer (MAO) simultaneously. In the Name treatment, subjects know their counterpart's gender from the experimental ID that explicitly signals gender, while in the Number treatment, they get three-digit IDs that contain no information about gender. We collect data from 495 pairs of players from two large universities: George Mason University (US) and Shanghai Jiao Tong University (China). Using two different subject pools sheds light on whether Solnick's findings on gender differences continue to hold with contemporary students in different cultures.

We observe little evidence of gender differences within either the US or Chinese subject pools. We do however find that US proposers are significantly more generous than Chinese proposers, and US responders are significantly more demanding than Chinese responders. Our inability to find gender differences in ultimatum bargaining suggests that these differences are context-based and do not seem to have a universal or constant pattern.

\section{Experimental design}

Following Solnick (2001), we use a one-shot strategy method ultimatum game with information about counterpart's gender either provided or not, depending on the treatment. The proposer and responder in a pair are asked to split an amount of money (\$20 in the US, RMB40 in China ${ }^{1}$ ). The proposer makes an offer specifying how much the responder will get, and at the same time, the responder specifies the minimum amount of money that he/she is willing to accept, which is the minimum acceptable offer (MAO). Both the offer and the MAO must be integers between 0 and total amount (inclusive). If the offer from the proposer is greater than or equal to the responder's MAO, the offer is accepted. Otherwise, the offer is rejected, and both players get 0 .

As in Solnick (2001), we conducted two treatments: Number and Name. In the Number treatment,

\footnotetext{
${ }^{1}$ In Solnick (2001), total amount to split was $\$ 10$ with a $\$ 2$ show-up bonus. The amounts paid in the US and China are equivalent in terms of purchasing power at University lunch providers, a relevant metric for most students.
} 
each subject was assigned a three-digit number ID with no information about gender. In the Name treatment, each subject was assigned a name ID according to their gender. Doing this ensures that the names in the experiment provide gender identification (many names in both the US and China are not gender specific) and also ensures anonymity.

Experiment procedures were identical between locations. All experiments were conducted using zTree (Fischbacher, 2007). We had equal numbers of males and females in each session to control beliefs about counterpart's gender. Upon arrival, subjects were randomly seated at partitioned computer terminals. They were then assigned an experimental ID (either a number or a name according to the treatment) and paired with another random person in the session. One was randomly chosen to be proposer and the other responder. An experimenter read aloud the instructions and distributed a quiz to ensure subjects understood the game. Subjects then saw their counterpart's experimental ID and made their decisions (offer or MAO) simultaneously. Before observing the outcome of the interaction, they filled out a questionnaire on demographic information, how they made their decision, what they would do if roles were reversed and their belief about their counterpart's decision. Then they were shown the outcome of the game, and were paid privately in cash. Subjects were in the lab for about 30 minutes.

Subjects were recruited from George Mason University (US) and Shanghai Jiao Tong University (China). Instructions were written in the local language. We conducted 24 sessions with a total of 490 subjects in US and 24 sessions with a total of 500 subjects in China in Fall 2016 and Spring 2017. No subject participated in more than one session. Average payments were $\$ 14.06$ (including $\$ 5$ show-up fee) and RMB27.62 (including RMB10 show-up fee) respectively.

Instructions, screenshots, as well as additional tables and graphs are given in the Electronic Supplementary Material.

\section{Results}

We collected data for 245 pairs in the US and 250 pairs in China (Table 1). Among the 245 pairs in the US, 174 pairs are in the Name treatment with 47 male proposers paired with male responders (M-M pairs), $43 \mathrm{M}-\mathrm{F}$ pairs, $37 \mathrm{~F}-\mathrm{M}$ pairs and $47 \mathrm{~F}-\mathrm{F}$ pairs. The other 71 pairs are in the Number treatment, with 41 males (M-UN) and 30 females (F-UN) being proposer, and 30 males (UN-M) and 41 females (UN-F) being responder, who did not know their counterpart's gender, and vice versa. ${ }^{2}$ While each pair in the Name treatment fits into exactly one of the four types of pairs, a pair in the Number treatment could fit into two categories. For instance, M-UN, F-UN and UN-M, UN-F describe a pair in the Number treatment either from the proposer's side or the responder's side. This explains the duplication of the shaded numbers in Table 1 below.

Among the 250 pairs in China, 178 pairs are in the Name treatment (48 M-M pairs, $36 \mathrm{M}-\mathrm{F}$ pairs, 46 F-M pairs and 48 F-F pairs). 72 pairs are in the Number treatment, with $35 \mathrm{M}-\mathrm{UN}$ pairs and 37 F-UN pairs, or $37 \mathrm{UN}-\mathrm{M}$ pairs and $35 \mathrm{UN}-\mathrm{F}$ pairs.

\footnotetext{
${ }^{2}$ Solnick (2001) collected data on 65 pairs in the Name treatment (22 M-M pairs, 14 M-F pairs, 16 F-M pairs and 13 F-F pairs) and 24 pairs in the Number treatment (12 M-UN pairs and 12 F-UN pairs, or 14 UN-M pairs and 10 UN-F pairs).
} 
Table 1 Number of Pairs by Type of Pair in Each Country

\begin{tabular}{|c|c|c|c|c|c|c|c|c|c|}
\hline & & \multicolumn{6}{|c|}{ Responder (R) } & & \\
\hline & & \multicolumn{2}{|c|}{ Male } & \multicolumn{2}{|c|}{ Female } & \multicolumn{2}{|c|}{$\begin{array}{l}\text { Gender } \\
\text { unknown to P }\end{array}$} & \multicolumn{2}{|c|}{ Total } \\
\hline & & USA & $\mathrm{CHN}$ & USA & $\mathrm{CHN}$ & USA & $\mathrm{CHN}$ & USA & $\mathrm{CHN}$ \\
\hline \multirow{4}{*}{$\begin{array}{l}\text { Proposer } \\
\text { (P) }\end{array}$} & Male & 47 & 48 & 43 & 36 & 41 & 35 & 131 & 119 \\
\hline & Female & 37 & 46 & 47 & 48 & 30 & 37 & 114 & 131 \\
\hline & $\begin{array}{l}\text { Gender } \\
\text { unknown to } \mathrm{R}\end{array}$ & 30 & 37 & 41 & 35 & - & - & - & - \\
\hline & Total & 114 & 131 & 131 & 119 & - & - & 245 & 250 \\
\hline
\end{tabular}

\subsection{Gender differences in each country}

Offers are reported in Table $2^{3}$. Within each country, average offers from male and female proposers are not significantly different. In the US subject pool, male proposers offer an average of 5.08 and female proposers offer an average of $5.03(\mathrm{p}=0.13)^{4}$. In the Chinese subject pool, male proposers offer an average of 4.78 and females offer an average of 4.71 ( $p=0.97)$. This is consistent with Solnick's (2001) finding.

Table 2 Offers by Type of Pair Average and Standard Error in Each Country

\begin{tabular}{|c|c|c|c|c|c|c|c|c|c|}
\hline & & \multicolumn{6}{|c|}{ Responder (R) } & \multirow{2}{*}{\multicolumn{2}{|c|}{ Average }} \\
\hline & & \multicolumn{2}{|c|}{ Male } & \multicolumn{2}{|c|}{ Female } & \multicolumn{2}{|c|}{$\begin{array}{l}\text { Gender } \\
\text { unknown to P }\end{array}$} & & \\
\hline & & USA & $\mathrm{CHN}$ & USA & $\mathrm{CHN}$ & USA & $\mathrm{CHN}$ & USA & $\mathrm{CHN}$ \\
\hline \multirow{6}{*}{$\begin{array}{l}\text { Proposer } \\
\text { (P) }\end{array}$} & Male & 5.00 & 4.68 & 5.15 & 5.03 & 5.09 & 4.65 & 5.08 & 4.78 \\
\hline & & $(0.19)$ & $(0.15)$ & $(0.05)$ & $(0.13)$ & $(0.19)$ & $(0.19)$ & $(0.09)$ & $(0.09)$ \\
\hline & Female & 5.11 & 4.63 & 4.96 & 4.67 & 5.03 & 4.85 & 5.03 & 4.71 \\
\hline & & $(0.23)$ & $(0.16)$ & $(0.14)$ & $(0.22)$ & $(0.18)$ & $(0.15)$ & $(0.11)$ & $(0.10)$ \\
\hline & Average & 5.05 & 4.65 & 5.05 & 4.82 & 5.06 & 4.75 & 5.05 & 4.74 \\
\hline & & $(0.15)$ & $(0.11)$ & $(0.08)$ & $(0.14)$ & $(0.13)$ & $(0.12)$ & $(0.07)$ & $(0.07)$ \\
\hline
\end{tabular}

Solnick (2001) main finding 1.1 (Women are offered less): Proposers offer significantly less to female responders than male responders. $(p=0.08)$

Our study (No gender difference in amounts offered to responders): Mean offers are not significantly affected by gender of responders in either of our subject pools.

Solnick (2001) finds that male responders attract more generous offers. We see no significant difference in offers to responders of each gender. Proposers offer an average of 5.05 to both male and female responders in the US sample ( $\mathrm{p}=0.50)$, and 4.65 to males and 4.82 to females in the Chinese sample ( $\mathrm{p}=0.45)$ (Fig. 1 Left).

\footnotetext{
${ }^{3}$ In order to compare easily across US, Chinese and Solnick's (2001) original data, we normalize all offers, MAOs and earnings to a maximum of 10. Specifically, we divide all offers, MAOs and earnings in the US sample by 2 and those in the Chinese sample by 4 .

${ }^{4}$ Unless noted otherwise, all p-values refer to two-sided Wilcoxon tests.
} 

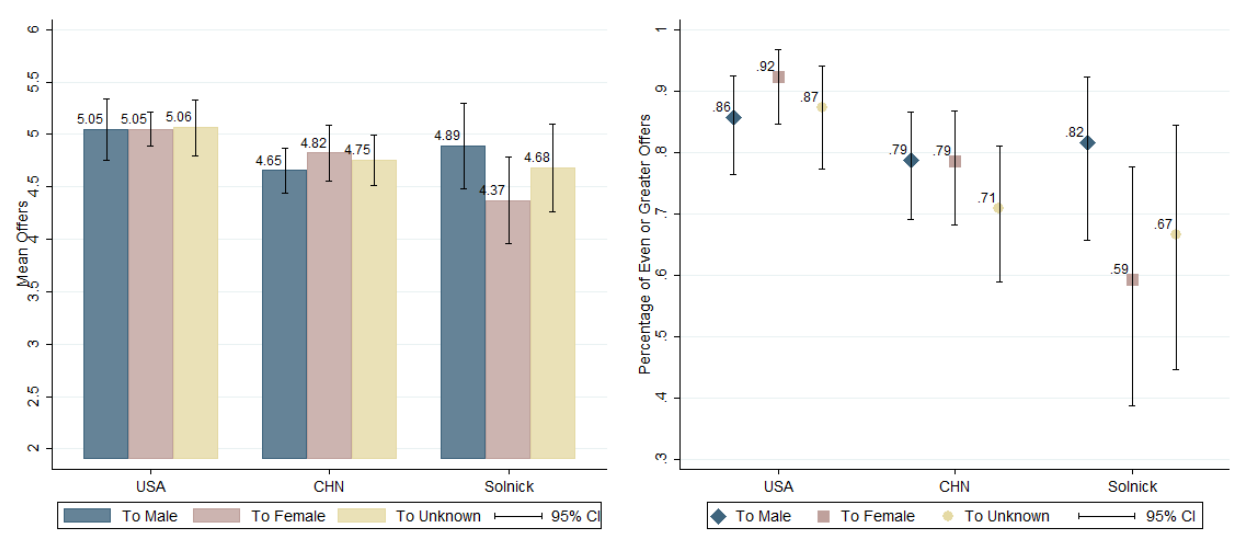

Fig. 1 Left: Mean Offers by Responder Gender in Each Country; Right: Percentage of Even or Greater Offers by Responder Gender in Each Country.

Solnick (2001) main finding 1.2 (Women are offered fewer favorable offers): $82 \%$ of offers to male responders are at least half; $59 \%$ of offers to female responders are at least half. ( $p=0.05$, z-test)

Our study (No gender difference in frequency of favorable offers): Female responders are offered equal or better splits at least as often as male responders, but the difference is not significant.

Regarding the frequency of favorable offers (Fig. 1 Right, Online Resource Table E1), which are offers greater than or equal to 5 , we find that female responders receive favorable offers $92 \%$ of the time in the US pool and $79 \%$ of the time in the Chinese pool, compared with $86 \%$ and $79 \%$ for male responders, though the difference is not significant (US: $p=0.17$; China: $p=0.98$ ). Further, in the US, male proposers offer female responders an equal or greater split $100 \%$ of the time, while they offer male responders at least an equal amount $81 \%$ of the time, which is a significant difference $(\mathrm{p}=0.003)$.

Table 3 records the MAOs. Solnick (2001) finds that female responders demand more (3.42, compared with males' MAO 2.81), but the difference is not significant ( $\mathrm{p}=0.14)$. Consistent with her results, we do not find that male and female responders demand differently in each country. Male and female responders in the US subject pool demand an average of 4.00 and 4.02 respectively ( $p=0.85)$. In the Chinese sample, males ask for an average of 3.42, and females $3.21 \quad(p=0.28)$.

Table 3 Minimum Acceptable Offers (MAOs) by Type of Pair Average and Standard Error in Each Country

\begin{tabular}{|c|c|c|c|c|c|c|c|}
\hline & & \multicolumn{4}{|c|}{ Responder (R) } & & \\
\hline & & \multicolumn{2}{|c|}{ Male } & \multicolumn{2}{|c|}{ Female } & \multicolumn{2}{|c|}{ Average } \\
\hline & & USA & $\mathrm{CHN}$ & USA & $\mathrm{CHN}$ & USA & $\mathrm{CHN}$ \\
\hline \multirow{8}{*}{$\begin{array}{l}\text { Proposer } \\
\text { (P) }\end{array}$} & Male & 3.91 & 3.18 & 3.88 & 3.17 & 3.90 & 3.18 \\
\hline & & $(0.25)$ & $(0.28)$ & $(0.26)$ & $(0.32)$ & $(0.18)$ & $(0.21)$ \\
\hline & Female & 4.39 & 3.10 & 4.09 & 3.07 & 4.22 & 3.08 \\
\hline & & $(0.25)$ & $(0.30)$ & $(0.19)$ & $(0.28)$ & $(0.15)$ & $(0.20)$ \\
\hline & Gender & 3.63 & 4.12 & 4.10 & 3.46 & 3.90 & 3.80 \\
\hline & unknown to $\mathrm{R}$ & $(0.29)$ & $(0.22)$ & $(0.22)$ & $(0.29)$ & $(0.17)$ & $(0.19)$ \\
\hline & Average & 4.00 & 3.42 & 4.02 & 3.21 & 4.01 & 3.32 \\
\hline & & $(0.15)$ & $(0.16)$ & $(0.13)$ & $(0.17)$ & $(0.10)$ & $(0.12)$ \\
\hline
\end{tabular}


Solnick (2001) main finding 2 (More demanded from females): Responders demand significantly more from female proposers than male proposers. $(p=0.01)$

Our study (No gender difference in amount demanded from proposers): Mean MAOs are not significantly affected by gender of proposers in either of our subject pools.

Solnick (2001) finds that female proposers elicit significantly higher MAOs from responders. In our data proposer's gender does not have significant impact on the responder's MAO (Fig. 2). In the US sample, average amount demanded from male proposers is 3.90 and from female proposers is 4.22 $(\mathrm{p}=0.38)$. In the Chinese sample, these two numbers are 3.18 and 3.08 respectively $(\mathrm{p}=0.76)$.

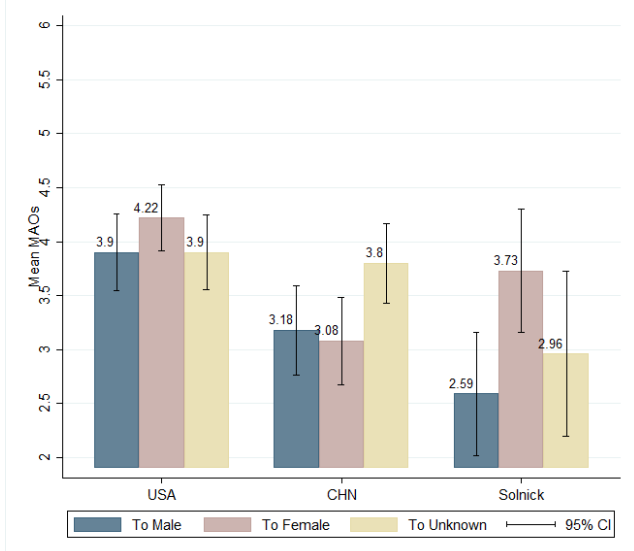

Fig. 2 Mean MAOs by Proposer Gender in Each Country

In Solnick's (2001) sample, pairs with female proposers have a significantly higher rejection rate than pairs with male proposers $(14.6 \%$ vs $4.2 \%, \mathrm{p}=0.08$, z-test). In our case, rejection rates of pairs with male proposers and pairs with female proposers do not differ significantly in either of our subject pools, nor do rejection rates of pairs with male responders and pairs with female responders (Online Resource Table E2 and Fig. E1).

Solnick (2001) main finding 3.1 (Male proposers earn more): Male proposers earn 14\% more than female proposers ( $p=0.44$, Wilcoxon test; $p=0.09$, t-test).

Our study (No gender difference in proposers' earnings): Earnings ${ }^{5}$ of male and female proposers do not differ significantly in either of our subject pools.

Solnick (2001) main finding 3.2 (Male responders earn more): Male responders earn 18\% more than female responders $(\mathrm{p}=0.10)$.

Our study (No gender difference in responders' earnings): Earnings of male and female responders do not differ significantly in either of our subject pools.

Solnick (2001) finds substantial gender differences in earnings, with females earning less both as proposers and responders. Females in our two samples do not earn less regardless of their role (Fig. 3, Online Resource Table E3 and Table E4). The US male proposers earn an average of 4.36 and the females earn $4.29(\mathrm{p}=0.38)$. The Chinese male proposers and female proposers earn an average of 4.17

\footnotetext{
5 As in Solnick (2001), earnings refer to amounts earned out of the ultimatum game.
} 
and 4.26 respectively $(\mathrm{p}=0.86$ ). As responders, US male subjects earn 4.68, compared with 4.78 earned by US females $(p=0.64)$. Chinese male and female responders earn 4.31 and 4.22 respectively $(p=0.92)$.
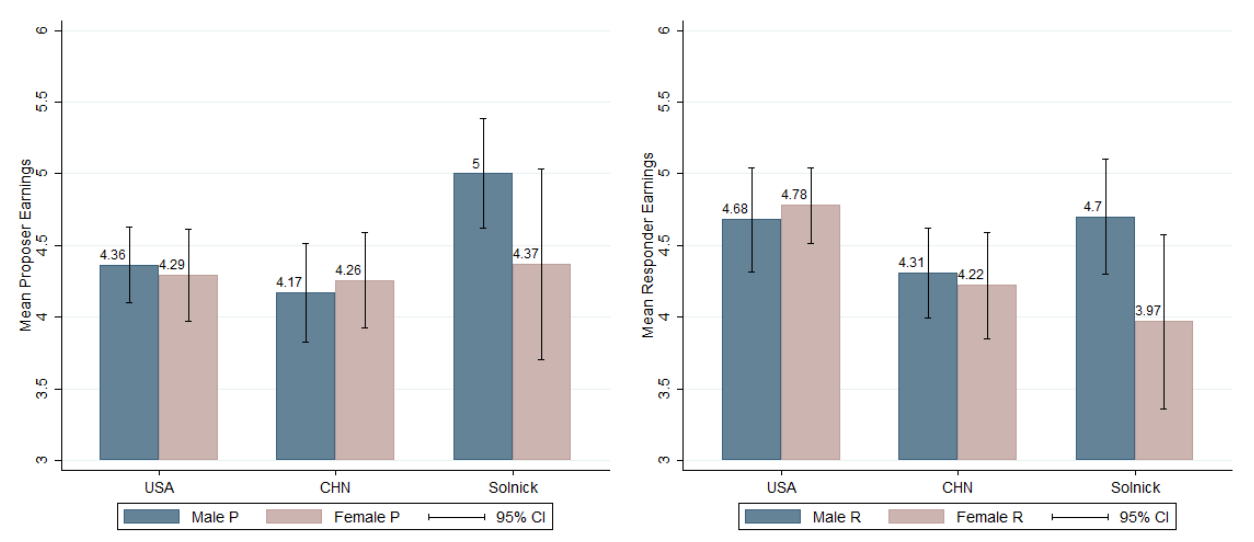

Fig. 3 Left: Mean Proposer Earnings in Each Country; Right: Mean Responder Earnings in Each Country

\subsection{Replication study power calculations}

Using the sample size in Table 1, we calculate the power of statistical tests for each Solnick's (2001) main findings (see Table 4). Our sample size is large enough to detect differences found in the original study at the $5 \%$ significance level.

Table 4 Power Calculations

\begin{tabular}{lcc}
\hline & $\begin{array}{c}\text { Power calculated from our sample size } \\
\text { at the 5\% significance level }\end{array}$ \\
\cline { 2 - 3 } Solnick (2001) Main Findings & USA & CHN \\
\hline 1.1 Women are offered less & 0.85 & 0.86 \\
\hline $\begin{array}{l}\text { 1.2 Women are offered fewer } \\
\text { favorable offers }\end{array}$ & 0.92 & 0.93 \\
\hline 2 More demanded from females & 0.997 & 0.997 \\
\hline 3.1 Male proposers earn more & 0.78 & 0.81 \\
\hline 3.2 Male responders earn more & 0.94 & 0.93 \\
\hline
\end{tabular}

\subsection{Behavioral differences between countries}

Although we find little evidence of gender effects within either subject pool, we do find differences between countries.

With respect to offers, US proposers are more generous than Chinese proposers, offering an average of 5.05 and 4.74 respectively $(\mathrm{p}=0.001)$. Offers in both the Name treatment (US: 5.05 vs China: 4.73, $\mathrm{p}=0.01$ ) and the Number treatment (US: 5.06 vs China: 4.75, $\mathrm{p}=0.02$ ) display this pattern.

US male proposers offer more than Chinese male proposers (Fig. 4). Males in our US sample offer an average of 5.08, while those in the Chinese sample offer 4.78 ( $p=0.002)$. In fact, each type of pair including US male proposers offer more (M-M, M-F, M-UN). US female proposers also offer 
more than Chinese female proposers, though the difference is not significant (US: 5.03, China: 4.71, $\mathrm{p}=0.13)$.

US male responders attract higher offers than Chinese male responders. Offers to males are 5.05 in US and 4.65 in China ( $\mathrm{p}=0.08$ ). Offers to female responders in the US is also higher than those to female responders in China (5.05 vs 4.82), though the difference is not significant ( $\mathrm{p}=0.12)$.

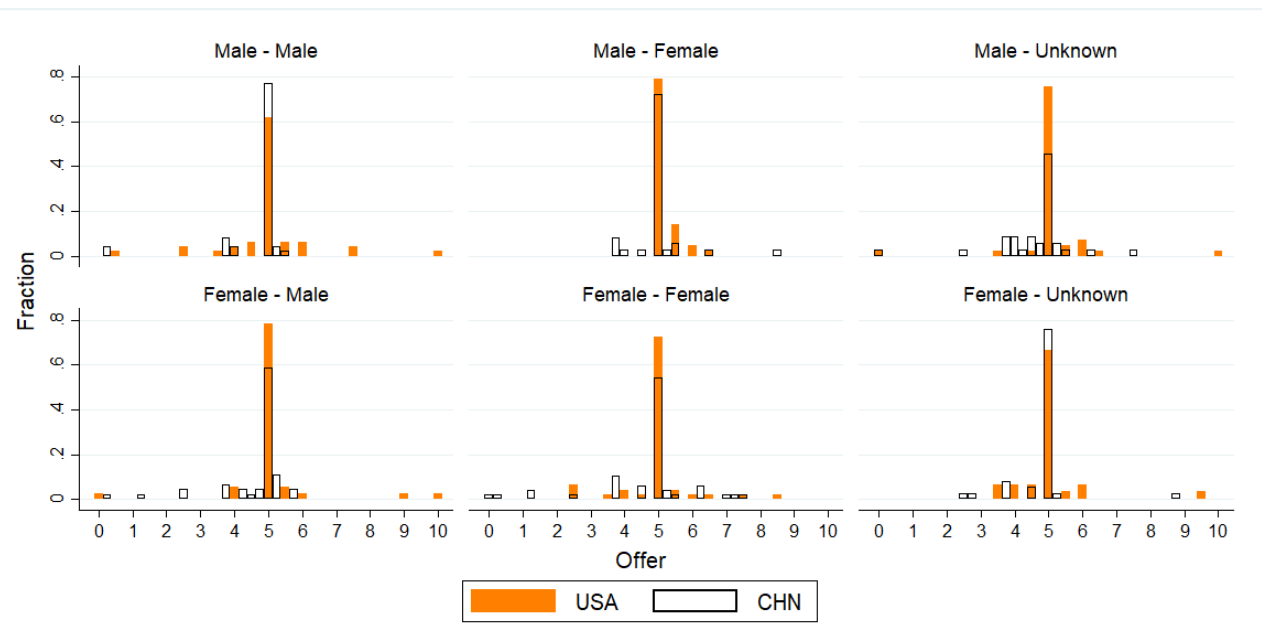

Fig.4 Distribution of Offers by Type of Pair (Proposer-Responder) between Countries: US proposers are more generous than Chinese proposers. US male proposers offer more on average (first row). US male responders receive higher offers on average (first column).

On the responder side, US responders report overall significantly higher MAOs than Chinese responders, with an average of 4.01 and 3.32 respectively $(p<0.001)$. This is true for both male responders (US: 4.00; China: 3.42, $\mathrm{p}=0.002$ ) and female responders (US: 4.02; China: 3.21, $\mathrm{p}<0.001$ ).

In fact, US responders ask for significantly more under each type of pair than Chinese responders (M-M US: 3.91, China: 3.18, $\mathrm{p}=0.01$; F-M US: 4.39, China: 3.10, $\mathrm{p}=0.001$; M-F US: 3.88, China: 3.17 , $\mathrm{p}=0.03$; F-F US: 4.09 , China: $3.07, \mathrm{p}=0.003$; UN-F US: 4.10 , China: $3.46, \mathrm{p}=0.08$ ) except for male responders in the Number treatment, where Chinese male responders demand more than US male responders, but not significant (UN-M US: 3.63, China: 4.12, p=0.28) (see Fig.5). This reversed relationship offsets the one for female responders and leads to no significant difference in average MAOs between countries in the Number treatment (US: 3.90, China: 3.80, $\mathrm{p}=0.59$ ).

US proposers are asked for significantly more than Chinese proposers in the Name treatment (US: 4.05, China: 3.13, $\mathrm{p}<0.001$ ), which applies to both male proposers (US: 3.90 , China: $3.18, p=0.001$ ) and female proposers (US: 4.22 , China: $3.08, \mathrm{p}<0.001$ ). 


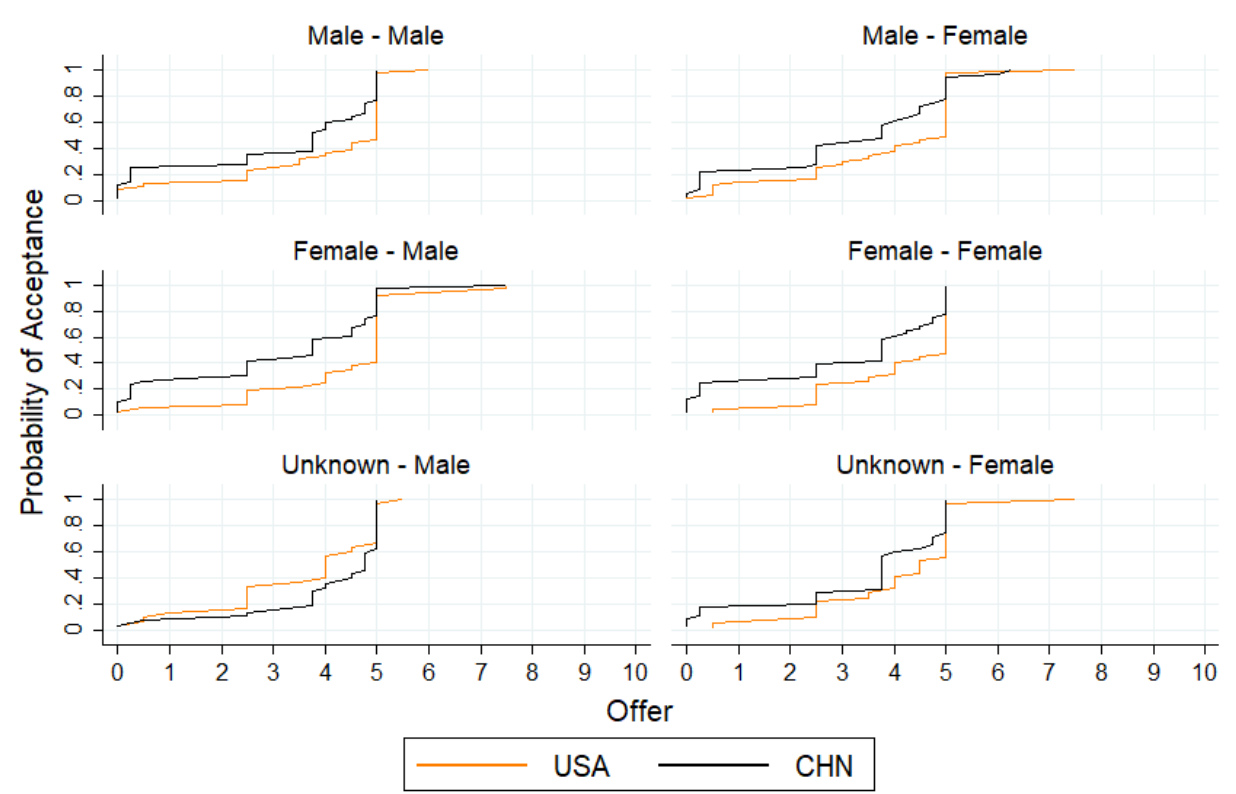

Fig.5 Probability of an Offer Being Accepted / CDF of MAOs by Type of Pair (Proposer-Responder) between Countries: Except for male responders in the Number treatment (UN-M pairs), MAOs demanded by responders are significantly higher in the US sample in all types of pairs.

With respect to rejection rates, the frequency is significantly higher in China (15.2\%) than the US $(9.4 \%, \mathrm{p}=0.05)$.

Average proposer earnings do not differ between these two countries ( 4.33 for US proposers, and 4.22 for Chinese proposers, $\mathrm{p}=0.78$ ). US responders earn significantly more than Chinese responders (4.73 compared with 4.27, $\mathrm{p}=0.004$ ) (Fig. 6). The reason is that rejection rates are significantly lower for US pairs, and US proposers offer more to responders.
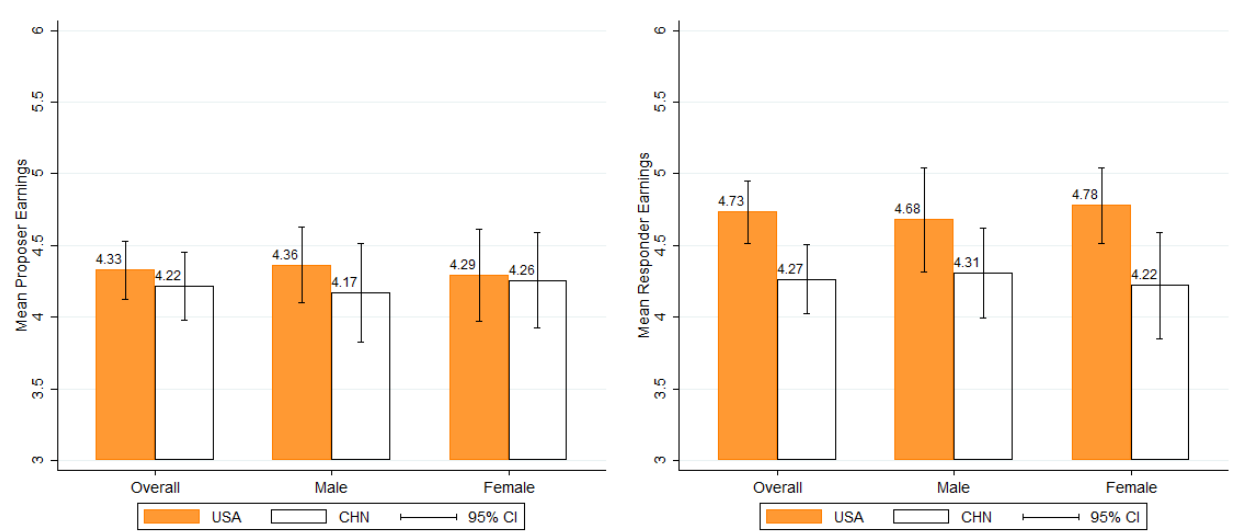

Fig. 6 Left: Mean Proposer Earnings between Countries; Right: Mean Responder Earnings between Countries

\section{Concluding remarks}

We conduct the Solnick (2001) gender differences in ultimatum game study using subjects from two large universities: George Mason University (US) and Shanghai Jiao Tong University (China). In the US 
sample, we find that male proposers treat female responders significantly better than male responders in that they offer them at least half of the total available amount $100 \%$ of the time. We do not observe any other gender difference in either China or the US. In particular, we were unable to replicate Solnick's (2001) key findings that more is demanded from female proposers, and less is offered to female responders.

However, we do find differences between the two locations. US proposers are more generous than Chinese proposers. In addition, US responders are more demanding than the Chinese responders. This suggests that proposers in both the US and China form correct beliefs about the expectations of their responders. Rejection rates in our Chinese sample are slightly higher, and US responders earn more on average than Chinese responders.

Cultural differences may have played a role in our data, which have been previously observed in ultimatum games (Oosterbeek et al., 2004; Chen and Tang, 2009). A potential explanation for this is differences in the survival/self-expression values of the US and China, one of the key cross-cultural variations noted by Inglehart (2000). Industrial societies like China emphasize economic and physical security, as well as materialist values, but offer relatively little support for gender equality. On the other hand, service or knowledge societies like the US value self-expression, subjective well-being and quality of life. As a result, compared with US subjects, Chinese proposers offer less, and responders demand less (getting something small is better than nothing).

Nevertheless, since our two subject pools are different from Solnick's (2001) in many ways including demographical and sociological backgrounds (for example, most subjects in our Chinese subject pool are the only child in the family as a result of the one-child policy), type of schools and school quality, among many other differences, it is difficult to conclude solely based on our inability to replicate Solnick's (2001) result that there has been positive social change towards women's position in bargaining. For the same reason, while we propose cultural differences as one possible explanation of the discrepancies we observe among our US and Chinese samples, at the same time, we cannot preclude behavioral differences caused by imperfect comparability between the subject pools.

We are comfortable however in suggesting that gender differences in bargaining are context-based and do not seem to have a universal or constant pattern. Differences may not be stable either across cultures or over time. The last decades have seen a concerted effort (especially in Western countries) to encourage women to engage in more competitive activities, and in particular to bargain more aggressively (see, e.g. Babcock and Laschever, 2003; Sandberg, 2013). While our results may paint an optimistic picture, more research needs to be done before we can know whether this effort has yielded social dividends. Our findings also raise important questions regarding the ability to accumulate knowledge in social sciences. Many well-known results might be better understood as a snapshot of a moment in time as compared to a foundational result upon which new knowledge can be built.

\section{References}

Ayres, I., \& Siegelman, P. (1995). Race and gender discrimination in bargaining for a new car. The American Economic Review, 304-321.

Babcock, L., \& Laschever, S. (2003). Women don't ask: Negotiation and the gender divide. Princeton University Press.

Blau, F. D., \& Kahn, L. M. (2016). The gender wage gap: Extent, trends, and explanations (No. w21913). National Bureau of Economic Research.

Castillo, M., Petrie, R., Torero, M., \& Vesterlund, L. (2013). Gender differences in bargaining outcomes: 
A field experiment on discrimination. Journal of Public Economics, 99, 35-48.

Chen, K., \& Tang, F. F. (2009). Cultural differences between Tibetans and ethnic Han Chinese in ultimatum bargaining experiments. European Journal of Political Economy, 25(1), 78-84.

Croson, R., \& Gneezy, U. (2009). Gender differences in preferences. Journal of Economic literature, 47(2), 448-474.

Dittrich, M., Knabe, A., \& Leipold, K. (2014). Gender differences in experimental wage negotiations. Economic Inquiry, 52(2), 862-873.

Eckel, C. C., \& Grossman, P. J. (2001). Chivalry and solidarity in ultimatum games. Economic Inquiry, 39(2), 171-188.

Fischbacher, U. (2007). z-Tree: Zurich toolbox for ready-made economic experiments. Experimental economics, 10(2), 171-178.

Güth, W., \& Kocher, M. G. (2014). More than thirty years of ultimatum bargaining experiments: Motives, variations, and a survey of the recent literature. Journal of Economic Behavior \& Organization, 108, $396-409$

Inglehart, R. (2000). Culture and democracy. Culture matters: How values shape human progress, 8097.

Oosterbeek, H., Sloof, R., \& Van De Kuilen, G. (2004). Cultural differences in ultimatum game experiments: Evidence from a meta-analysis. Experimental Economics, 7(2), 171-188.

Saad, G., \& Gill, T. (2001). Sex differences in the ultimatum game: An evolutionary psychology perspective. Journal of Bioeconomics, 3(2-3), 171-193.

Sandberg, S. (2013). Lean in: Women, work, and the will to lead. Random House.

Solnick, S. J. (2001). Gender differences in the ultimatum game. Economic Inquiry, 39(2), 189.

Sutter, M., Bosman, R., Kocher, M. G., \& van Winden, F. (2009). Gender pairing and bargainingBeware the same sex!. Experimental Economics, 12(3), 318-331. 


\section{Electronic Supplementary Material}

\section{Contents}

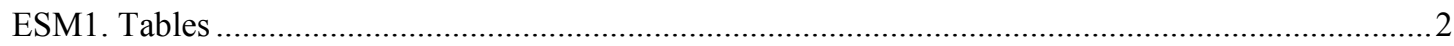

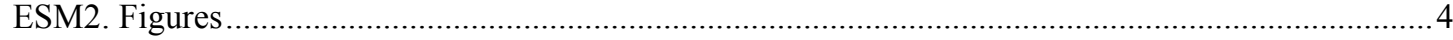

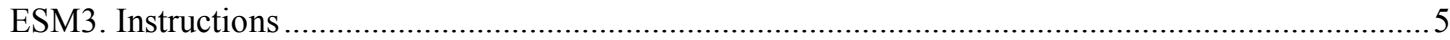

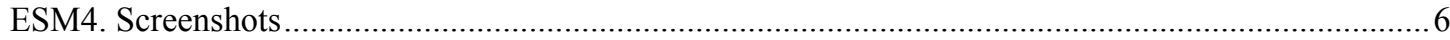




\section{ESM1. Tables}

Table E1 Percentages of Even or Greater Offers by Type of Pair in Each Country

\begin{tabular}{|c|c|c|c|c|c|c|c|c|c|}
\hline & & \multicolumn{6}{|c|}{ Responder (R) } & \multirow{2}{*}{\multicolumn{2}{|c|}{ Total }} \\
\hline & & \multicolumn{2}{|c|}{ Male } & \multicolumn{2}{|c|}{ Female } & \multicolumn{2}{|c|}{$\begin{array}{l}\text { Gender } \\
\text { unknown to } \mathrm{P}\end{array}$} & & \\
\hline & & USA & $\mathrm{CHN}$ & USA & $\mathrm{CHN}$ & USA & $\mathrm{CHN}$ & USA & $\mathrm{CHN}$ \\
\hline \multirow{6}{*}{$\begin{array}{l}\text { Proposer } \\
\text { (P) }\end{array}$} & Male & $81 \%$ & $83 \%$ & $100 \%$ & $86 \%$ & $93 \%$ & $60 \%$ & $91 \%$ & $77 \%$ \\
\hline & & $(38 / 47)$ & $(40 / 48)$ & $(43 / 43)$ & $(31 / 36)$ & $(38 / 41)$ & $(21 / 35)$ & $(119 / 131)$ & $(92 / 119)$ \\
\hline & Female & $92 \%$ & $74 \%$ & $85 \%$ & $73 \%$ & $80 \%$ & $81 \%$ & $86 \%$ & $76 \%$ \\
\hline & & $(34 / 37)$ & $(34 / 46)$ & $(40 / 47)$ & $(35 / 48)$ & $(24 / 30)$ & $(30 / 37)$ & $(98 / 114)$ & $(99 / 131)$ \\
\hline & Total & $86 \%$ & $79 \%$ & $92 \%$ & $79 \%$ & $87 \%$ & $71 \%$ & $89 \%$ & $76 \%$ \\
\hline & & $(72 / 84)$ & $(74 / 94)$ & $(83 / 90)$ & $(66 / 84)$ & $(62 / 71)$ & $(51 / 72)$ & $(217 / 245)$ & $(191 / 250)$ \\
\hline
\end{tabular}

Note: Number of observations in parentheses.

Table E2 Rejection Rates by Type of Pair in Each Country

\begin{tabular}{|c|c|c|c|c|c|c|c|c|c|}
\hline & & \multicolumn{4}{|c|}{ Responder (R) } & \multirow{2}{*}{\multicolumn{2}{|c|}{$\begin{array}{l}\text { Gender unknown to } \\
\mathrm{P}\end{array}$}} & \multirow{2}{*}{\multicolumn{2}{|c|}{ Total }} \\
\hline & & \multicolumn{2}{|c|}{ Male } & \multicolumn{2}{|c|}{ Female } & & & & \\
\hline & & USA & $\mathrm{CHN}$ & USA & $\mathrm{CHN}$ & USA & $\mathrm{CHN}$ & USA & $\mathrm{CHN}$ \\
\hline \multirow{8}{*}{$\begin{array}{l}\text { Proposer } \\
\text { (P) }\end{array}$} & Male & $14.9 \%$ & $10.4 \%$ & $2.3 \%$ & $11.1 \%$ & $7.3 \%$ & $28.6 \%$ & $8.4 \%$ & $16.0 \%$ \\
\hline & & $(7 / 47)$ & $(5 / 48)$ & $(1 / 43)$ & $(4 / 36)$ & $(3 / 41)$ & $(10 / 35)$ & $(11 / 131)$ & $(19 / 119)$ \\
\hline & Female & $10.8 \%$ & $13.0 \%$ & $10.6 \%$ & $14.6 \%$ & $10.0 \%$ & $16.2 \%$ & $10.5 \%$ & $14.5 \%$ \\
\hline & & $(4 / 37)$ & $(6 / 46)$ & $(5 / 47)$ & $(7 / 48)$ & $(3 / 30)$ & $(6 / 37)$ & $(12 / 114)$ & $(19 / 131)$ \\
\hline & Gender & $6.7 \%$ & $18.9 \%$ & $9.8 \%$ & $25.7 \%$ & - & - & $8.5 \%$ & $22.2 \%$ \\
\hline & $\begin{array}{l}\text { unknown } \\
\text { to } \mathrm{R}\end{array}$ & $(2 / 30)$ & $(7 / 37)$ & $(4 / 41)$ & $(9 / 35)$ & - & - & $(6 / 71)$ & $(16 / 72)$ \\
\hline & Total & $11.4 \%$ & $13.7 \%$ & $7.6 \%$ & $16.8 \%$ & $8.5 \%$ & $22.2 \%$ & $9.4 \%$ & $15.2 \%$ \\
\hline & & $(13 / 114)$ & $(18 / 131)$ & $(10 / 131)$ & $(20 / 119)$ & $(6 / 71)$ & $(16 / 72)$ & $(23 / 245)$ & $(38 / 250)$ \\
\hline
\end{tabular}

Note: Number of observations in parentheses.

Table E3 Actual Proposer Earnings by Type of Pair Average and Standard Error in Each Country

\begin{tabular}{|c|c|c|c|c|c|c|c|c|c|}
\hline & & \multicolumn{6}{|c|}{ Responder (R) } & \multirow{2}{*}{\multicolumn{2}{|c|}{ Average }} \\
\hline & & \multicolumn{2}{|c|}{ Male } & \multicolumn{2}{|c|}{ Female } & \multicolumn{2}{|c|}{$\begin{array}{l}\text { Gender } \\
\text { unknown to } \mathrm{P}\end{array}$} & & \\
\hline & & USA & $\mathrm{CHN}$ & USA & $\mathrm{CHN}$ & USA & $\mathrm{CHN}$ & USA & $\mathrm{CHN}$ \\
\hline \multirow{6}{*}{$\begin{array}{l}\text { Proposer } \\
\text { (P) }\end{array}$} & Male & 4.00 & 4.53 & 4.73 & 4.33 & 4.39 & 3.50 & 4.36 & 4.17 \\
\hline & & $(0.28)$ & $(0.23)$ & $(0.12)$ & $(0.28)$ & $(0.24)$ & $(0.39)$ & $(0.13)$ & $(0.17)$ \\
\hline & Female & 4.19 & 4.42 & 4.31 & 4.21 & 4.38 & 4.11 & 4.29 & 4.26 \\
\hline & & $(0.30)$ & $(0.27)$ & $(0.24)$ & $(0.29)$ & $(0.32)$ & $(0.32)$ & $(0.16)$ & $(0.17)$ \\
\hline & Average & 4.08 & 4.48 & 4.51 & 4.26 & 4.39 & 3.82 & 4.33 & 4.22 \\
\hline & & $(0.20)$ & $(0.18)$ & $(0.14)$ & $(0.21)$ & $(0.19)$ & $(0.25)$ & $(0.10)$ & $(0.12)$ \\
\hline
\end{tabular}


Table E4 Actual Responder Earnings by Type of Pair Average and Standard Error in Each Country

\begin{tabular}{llccccccc}
\hline & & \multicolumn{3}{c}{ Responder (R) } \\
\cline { 3 - 8 } & & \multicolumn{2}{c}{ Male } & \multicolumn{2}{c}{ Female } & \multicolumn{2}{c}{ Average } \\
\cline { 2 - 8 } $\begin{array}{l}\text { Proposer } \\
\text { (P) }\end{array}$ & Male & 4.51 & 4.43 & 5.03 & 4.56 & 4.76 & 4.48 \\
\cline { 2 - 8 } & & $(0.31)$ & $(0.22)$ & $(0.13)$ & $(0.30)$ & $(0.17)$ & $(0.18)$ \\
\cline { 2 - 8 } & Female & 4.73 & 4.27 & 4.63 & 4.33 & 4.67 & 4.30 \\
\cline { 2 - 8 } & & $(0.33)$ & $(0.26)$ & $(0.26)$ & $(0.29)$ & $(0.20)$ & $(0.20)$ \\
\cline { 2 - 8 } & Gender & 4.88 & 4.19 & 4.68 & 3.72 & 4.77 & 3.96 \\
\cline { 2 - 8 } & unknown to R & $(0.30)$ & $(0.36)$ & $(0.27)$ & $(0.38)$ & $(0.20)$ & $(0.26)$ \\
\hline & Average & 4.68 & 4.31 & 4.78 & 4.22 & 4.73 & 4.27 \\
\hline
\end{tabular}




\section{ESM2. Figures}
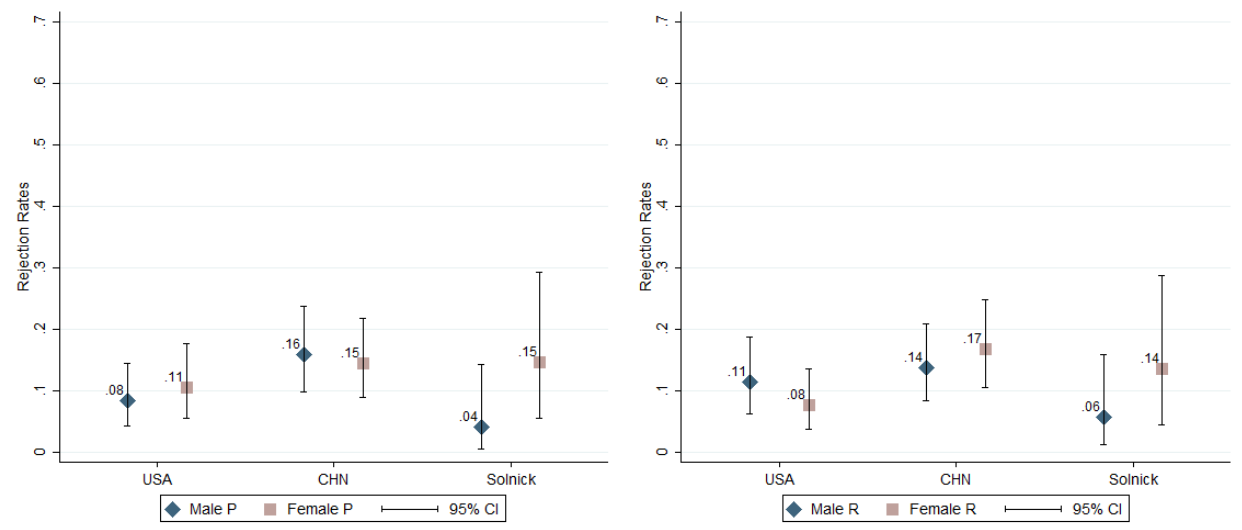

Fig. E1 Left: Rejection Rates by Proposer Gender in Each Country; Right: Rejection Rates by Responder Gender in Each Country 


\section{ESM3. Instructions}

\section{Instructions (Name Treatment) ${ }^{7}$}

Thank you for coming to this experiment.

Please turn off all electronic devices and place them in your bags. Please keep quiet and remain seated during the experiment. If you have any questions, raise your hand and we will come to personally assist you.

All participants will receive a payment of $\$ 5$ for showing up on time. In addition, if you follow the instructions carefully, you can earn more money based on your decision and the decision of other participants. At the end of the experiment, you will be paid privately in cash.

Upon arrival, every one of you has been randomly assigned an experimental ID which will be shown to you on the screen soon. This ID identifies your decision today, and no one including the experimenters will be able to link your decision to your name. Please keep it private to yourself. Note that this ID is an artificial first name that is assigned according to your gender. ${ }^{8}$

The decision task is a two-person money-splitting game between Proposer and Responder. You have been randomly paired with another participant in this room, who becomes your counterpart. One of you is randomly chosen to be Proposer and the other Responder. You will see your role and your counterpart's ID on the screen before making any decision.

The Proposer and Responder in a pair have \$20 to split. On the decision screen, the Proposer makes an offer specifying how much of the $\$ 20$ the Responder will get. At the same time, the Responder inputs the minimum amount of money out of $\$ 20$ that he/she is willing to accept (the minimum acceptable offer). The offer and the minimum acceptable offer must be integers between 0 and 20 (inclusive). Neither of them will see each other's input until the end of the experiment. If the offer from the Proposer is greater than or equal to the Responder's minimum acceptable offer, this offer is accepted; the Responder gets the offer, and the Proposer gets the rest (=20-offer). Otherwise, the offer is rejected, and both players get $\$ 0$.

A questionnaire follows the decision task.

After the questionnaire, you will see on the screen results of the decision task and your profits.

Let us know if you have any questions. To make sure you understand these instructions, we will distribute a quiz now.

\footnotetext{
7 Instructions in Chinese are available upon request.

${ }^{8}$ For Number Treatment, this sentence is replaced by "Note that this ID is a three-digit number."
} 
ESM4. Screenshots ${ }^{9}$

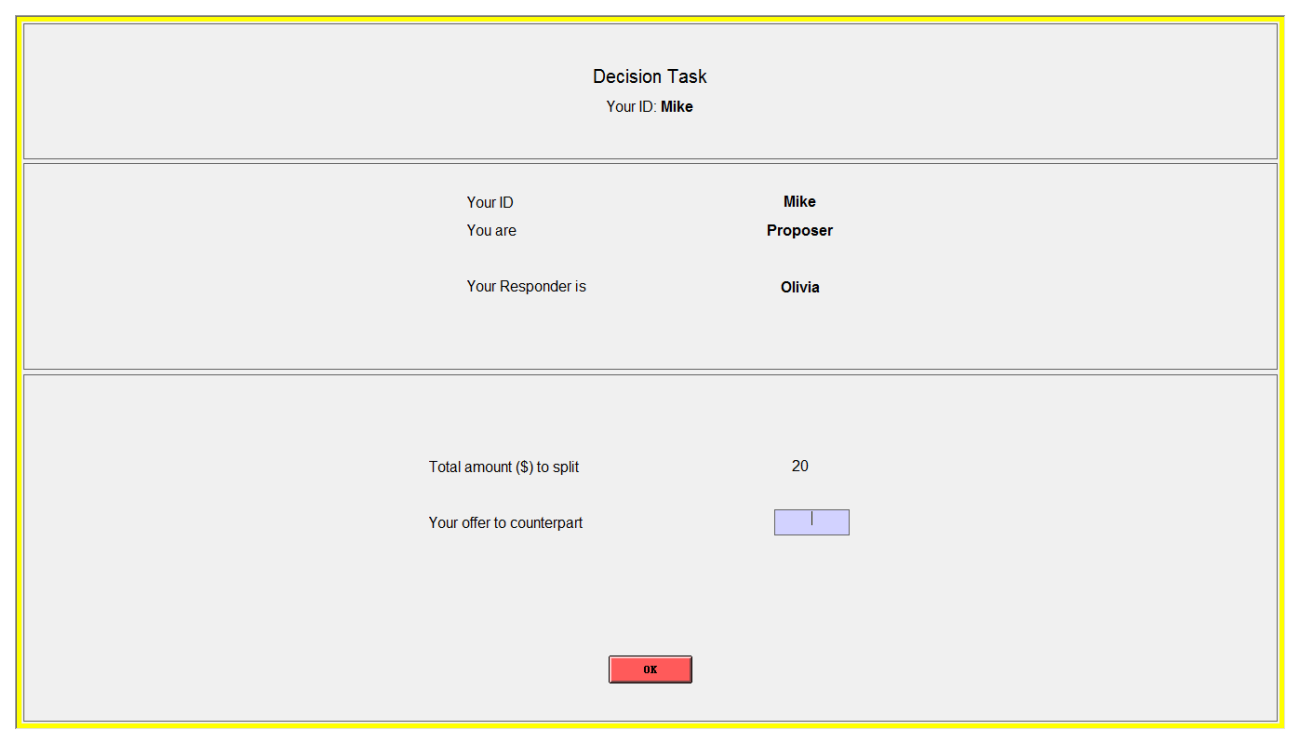

Fig. E2 Decision Task Interface for the Proposer (Name Treatment)

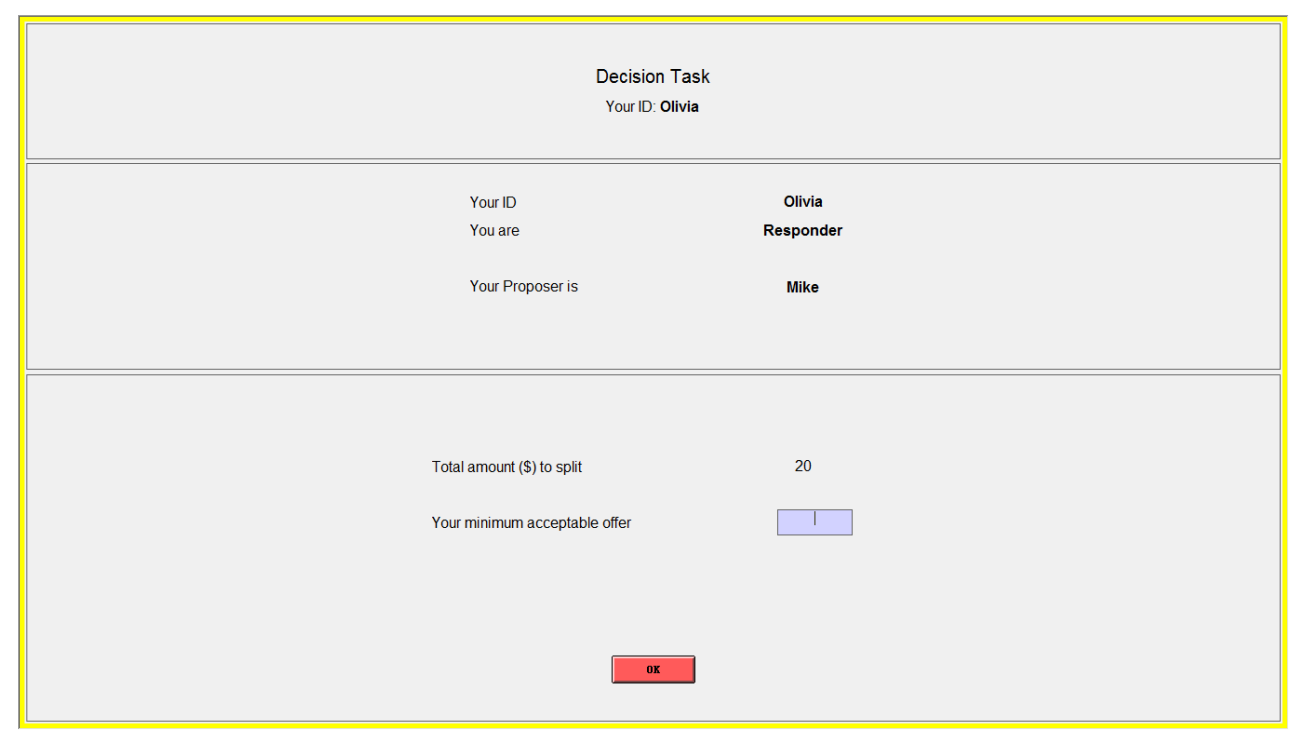

Fig. E3 Decision Task Interface for the Responder (Name Treatment) 


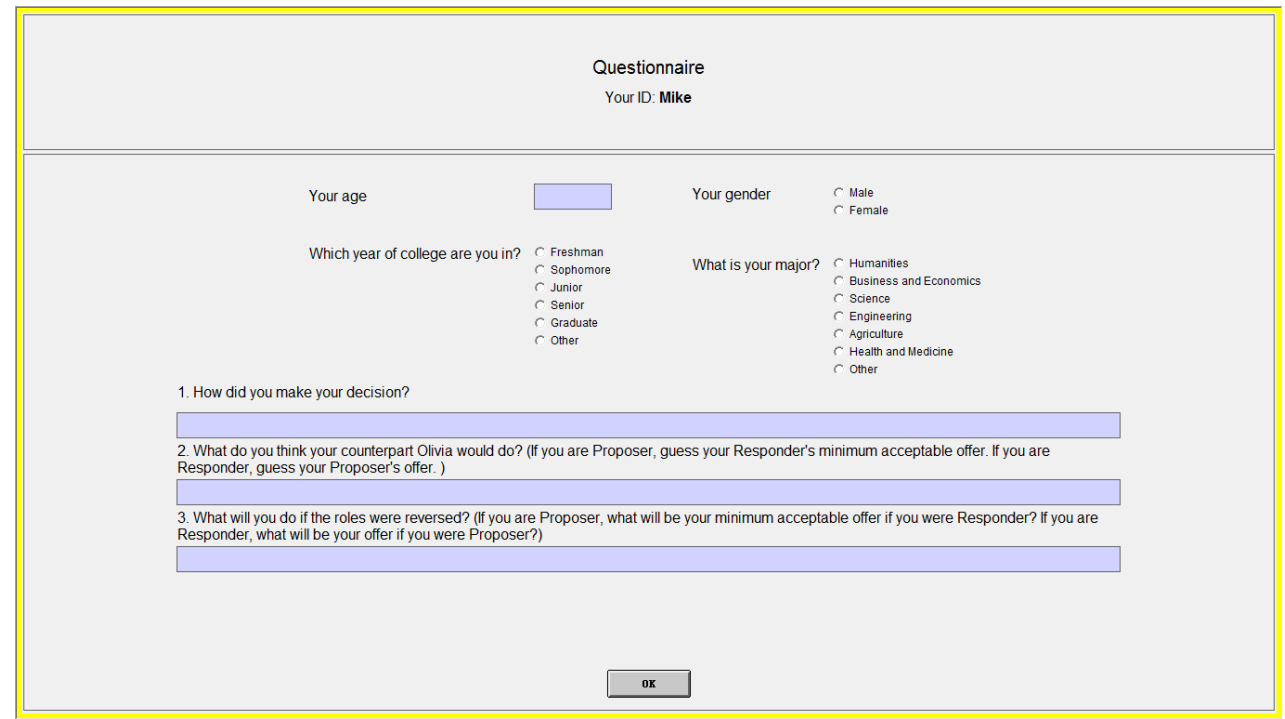

Fig. E4 Questionnaire (Name Treatment)

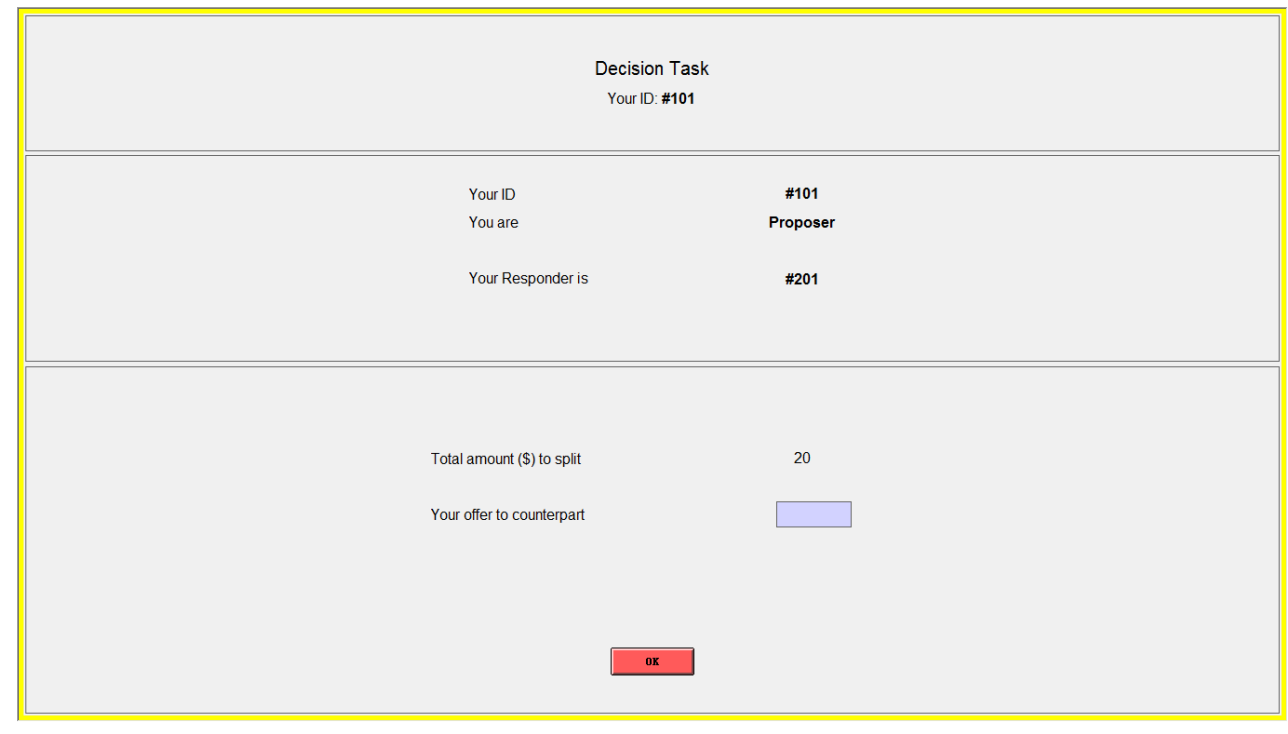

Fig. E5 Decision Task Interface for the Proposer (Number Treatment) 